\title{
Gray based Fuzzy Gain-Scheduling PID Controller Design for Air- Fuel System Under Variable Engine Operating Conditions
}

\author{
Alirıza Kaleli \\ Department of Engineering, Samsun University, 55420, Samsun, Turkey.
}

\begin{abstract}
In this study, the problem of regulation of air-fuel ratio (AFR) in gasoline engines under different engine operating conditions is discussed. Firstly, the mean value mathematical model of the AFR system has been created. Then, two different approaches named with classical proportional-integral-derivative (PID) and a fuzzy logic gain scheduling PID controller combined with gray system modelling approach (Gray GS-PID)have been used to improve the performance of the engine to monitor stoichiometric conditions. The parameters of classical PID parameters are determined by the pattern search algorithm. The design procedures for both controllers have been presented in detail. In order to evaluate the performance analysis for both of the proposed controllers, variable conditions were established based on engine speed and throttle opening ratios in the US06 and UDDS driving conditions and validated by simulation results. According to the results, Gray GS_PID is more powerful than optimally adjusted PID in terms of reducing the amount of deviation of AFR from stoichiometric value under variable engine operating conditions. The most important contribution of this study is that, unlike conventional AFR regulation, the prediction of future error value relative to the previous AFR error values using the gray prediction algorithm, and the design of the control algorithm that determines the control action for the next step depending on the predicted error value before the error occurs and sets the gain parameters.
\end{abstract}

Keywords: AFR system, GM(1,1) predictive model, Fuzzy logic, Gain scheduling PID

\section{INTRODUCTION}

Today, gasoline engine fuel injection systems are equipped with control units that monitor the reference signal of the air-fuel ratio (AFR) to improve fuel consumption and reduce exhaust emissions. These systems keep the AFR close to the stoichiometric conditions to maximize the efficiency of the catalytic converter. If the AFR exceeds the by $1 \%$, it causes NOx emission to increase by about $50 \%$, on the other hand, if it falls $1 \%$ below the stoichiometric value it causes an increase significantly in $\mathrm{CO}$ and $\mathrm{HC}$ emissions [1].

In the literature, many model-based and closed-loop controller designs have been proposed for the air-fuel ratio control problem. Franceschi, Muske et al., have proposed a discrete-time, time-delayed PID controller for the air-fuel ratio for a gasoline engine [2]. In this study, the relationship between two time delays and engine speed and load parameters has been investigated. These are delays from the fuel injection to the exhaust manifold, and the interior dynamic behaviour of the UEGO sensor. In [3], the variable dynamics of the engine has been considered, and a model-based linear quadratic control algorithm has been designed for the reg- ulation of AFR. Since the internal dynamics of the engine change over time, in another study, a minimum phase system has been obtained with Pade's approach and unknown parameters have been estimated in the study carried out by Ebrahami et al. [4]. In this study, a variable parameter PID controller has been used in the closed-loop control system.

In addition to the PID controller, nonlinear control systems have also been designed for the AFR system in the literature. Cho and Hendrick have presented the mean value engine model (MVEM) for the engine air path system and have developed a nonlinear sliding mode controller for fuel injection system [5]. The AFR has been kept within the $14.7 \pm 0.2$ band, a method that prevented chattering due to the nature of sliding-mode controllers has not been proposed in this study. Although these linear and nonlinear control methods are applied in AFR control, the controllers are affected by non-measurable signals from the inside and outside of the engine. This situation has necessitated the design of an AFR controller that is more resistant to disturbing effects. Therefore, the development of microprocessor hardware has enabled the use of different algorithms in the regulation of AFR
* Corresponding authour

Email: arizakaleli@gmail.com
European Mechanical Science, December 2019; 3(4): 125-132 doi: https://doi.org/10.26701/ems.599452

Received: July 31, 2019

Accepted: November 20, 2019 
[6-7].In the internal combustion engine control systems, the signals that have the disturbing effect mentioned are called gray signals in terms of system identification techniques, and such systems are also called gray systems [11,12]. It is of great importance to reduce the effects of disturbance signals in these systems. For this purpose, observer and prediction algorithms are used in the field of system theory. Gray predictors can predict the future value of the system even if there is not enough information about the system [13]. Gray system predictors with a certain prediction capability offer a different approach to conventional control methods in closed-loop control systems. In conventional systems, current error information is used as a feedback signal, whereas in systems with gray predictors, the value of the error in the next step is predicted [12].

It is difficult to obtain mathematical models precisely in real-time systems. This situation causes a decrease in the expected success rate of linear controllers. In this case, fuzzy logic theory and fuzzy controllers show some advantages. However, there are some negative cases encountered in practice, in the fuzzy controllers. Particularly, determining the number of design parameters is a very difficult process. These parameters vary according to the system when the fuzzy controller is applied while it is only three in the traditional PID controller. Several methods have been proposed in the literature on the determination of the parameters of PID controllers [14-15]. Unlike conventional PID, parameter determination using fuzzy logic theory is more advantageous. This makes the PID controller more insensitive to uncertain cases in the system.

In this study, the rule-based, gain-scheduling PID controller combined with the gray system approach has been proposed to regulate the air-fuel ratio (AFR) of a gasoline engine considering its nonlinear and uncertain structure. When selecting the AFR controller on the internal combustion engines, it is necessary to consider the fact that the engine is able to respond to instantaneous changes and to be least affected by uncertainty and disturbing signals such as instantaneous speed and load changes. Accordingly, in the first part of the study, the MVEM of the AFR system has been created in Matlab/Simulink environment. Following the modelling of the system, conventional PID and proposed controller approaches have been applied separately on the model. Pattern Search optimization method has been used to determine the conventional PID controller parameters. Finally, both controllers have been tested separately under different engine operating conditions to investigate AFR change. As a result of the analysis, it has been observed that the deviation of AFR from the given stoichiometric value decreased. Additionally, the mean square error (MSE) of the proposed controller between the desired and obtained AFR values has been found to be lower than that of the conventional PID system. The results obtained have been presented both graphically and in tabular form.

\section{MATERIALS AND METHODS}

\subsection{Mean Value Model of Gasoline Engine for AFR Dynamics}

As is known, the amount of air in gasoline engines is regulated by the throttle, while the AFR $(\lambda)$ is controlled by the fuel injection control system. Here, $\lambda=14.6$ refers to the stoichiometric mixing ratio and is an important mode of engine operation in reducing emissions in the engines used in today's vehicles with a three-way catalyst (TWC). To confirm the result of the proposed AFR controller, a spark-ignition engine is used which is schematically shown in Fig. 1. In Table 1, the parameters used in Fig. 1 are explained. In this study, engine model was obtained by using the MVEM. Intake manifold, fuel injection system and crankshaft are used as subsystems. In the modelled system, the inputs are fuel flow, throttle opening ratio and ignition signals.

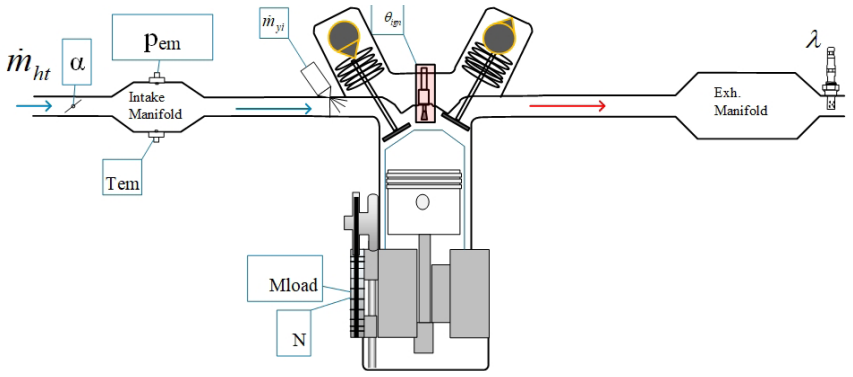

Fig. 1. Schematic diagram of a gasoline engine

Table 1. The parameters used in Fig. 1

\begin{tabular}{|l|c|}
\hline Parameters & \\
\hline The mass flow rate of the air in the intake manifold & $\dot{m}_{h t}$ \\
\hline Intake manifold pressure & $p_{e m}$ \\
\hline Intake air temperature & $T_{e m}$ \\
\hline The mass flow rate of the fuel & $\dot{m}_{y i}$ \\
\hline Ignition advance & $\theta_{i n}$ \\
\hline Air-fuel ratio (AFR) & $\lambda$ \\
\hline Engine load & $M_{y u k}$ \\
\hline
\end{tabular}

\subsection{Throttle and Intake Manifold Air Flow System}

In gasoline engines, the throttle valve is used to control the mass flow rate of air entering the engine. The throttle angle, intake air temperature, and other factors affect the airflow rate entering the combustion chamber. The air path dynamics is expressed as in Eq. 1 under the ideal gas assumption.

$$
\frac{d P_{e m}}{d t}=\frac{R T_{e}}{V_{e}}\left(\dot{m}_{h t}-\dot{m}_{h s}\right)
$$

$\dot{m}_{h t}$ indicates the airflow rate in the intake manifold changing with the angle of the throttle valve. Because the cross-sectional area of the throttle valve is small and the pressure difference between the inlet and outlet is large, the flow in the throttle is considered as compressible isentropic flow [17]. The pressure ratio between the inlet and outlet of the throttle is expressed as $P_{r}=\frac{P_{e m}}{P_{a m b}}$. Thus, the mass flow rate of the air through the throttle can be written as in 


$$
\begin{aligned}
& \dot{m}_{h t}=\frac{P_{a m b}}{\sqrt{R T_{a m b}}} A(\alpha) C_{D}(\alpha) \psi\left(P_{r}\right) \\
& \psi\left(P_{r}\right)=\left\{\begin{array}{ll}
\sqrt{\frac{2 \varkappa}{\varkappa-1}\left(1-\frac{P_{e m} \frac{x-1}{x}}{P_{a m b}}\right)}, \frac{P_{e m}}{P_{a m b}} \geq \frac{2 \varkappa^{\frac{x-1}{x}}}{\varkappa-1} \\
\sqrt{\varkappa\left(\frac{2 \varkappa^{\frac{x-1}{x+1}}}{\varkappa-1}\right)}, \frac{P_{e m}}{P_{a m b}}<\frac{2 \varkappa^{\frac{x-1}{x}}}{\varkappa-1}
\end{array}\right\} \\
& A(\alpha)=\pi D^{2}\left(1-\frac{\cos (\alpha)}{\cos \left(\alpha_{0}\right)}\right)
\end{aligned}
$$

$A(\alpha)$ indicates the area of the throttle depending on the angle. $\alpha \_0$ represents the small gap ratio when the butterfly is in the closed position, and $D$ is the diameter of the butterfly. $C_{D}(\alpha)$ is a design parameter of the throttle valve and different methods have been proposed in the literature to calculate it [5]. $\psi(\cdot)$ is a flow-dependent function. Additionally, $\dot{m}_{h s}$ indicates the airflow rate through the intake valves into the cylinder. This parameter can be defined in relation with the volumetric efficiency as follows,

$$
\dot{m}_{h s}=\eta \frac{V_{D} N P_{e m}}{n_{r} R T_{e m}}
$$

where $V_{D}$ is the stroke volume, $N$ is the engine speed, $P_{e m}$ is the intake manifold pressure and $T_{e m}$ is the intake air temperature. $n_{r}$ is taken as 1 for two-stroke engines and 2 for four-stroke engines. In this study, the mapping method prepared according to engine speed and intake manifold pressure was used for volumetric efficiency in Eq. 3.

\subsection{Fuel injection and exhaust systems}

The fuel flow into the cylinder is provided by the fuel injectors controlled by the engine electronic control unit. Multiplying the amount of fuel injected into the cylinder during one engine cycle by the engine speed gives the total fuel flow rate through the injector [17].

$$
\dot{m}_{y i}=\frac{N n_{c y l}}{n_{r}} m_{y i}
$$

After modelling the fuel and air entering the cylinder, the AFR $(\lambda)$ has been modelled. The controller can simply calculate the fuel to be injected according to the stoichiometric ratio after determining the air entering the cylinder, Lamda is mathematically expressed in

$$
\lambda_{s}=\frac{\dot{m}_{h s}}{\dot{m}_{y i}} \frac{1}{(A / F)_{s}}
$$

After the fuel is injected into the intake manifold, there will be a time delay between the detection of combustion products up to the point in the exhaust line where the lambda sensors are located. The time delay is basically divided into two parts. The first part is related to the engine speed and indicated by $\tau_{c}=720 / 60 \mathrm{~N}$. The second is the time taken for the exhaust gases to reach the sensor from opening the valve $\tau_{g}=\delta / \dot{\mu}_{h s} . \delta$ is an experimentally obtained parameter. Therefore, the total delay is calculated as $\tau=\tau_{c}+\tau_{g}$. In this study, the broadband UEGO sensor is modelled as a first-order system. Transfer function used has been given in

$$
G(s)=1 / \tau_{s} s+1
$$

where, the time constant of UEGO.

\subsection{The crankshaft system}

Another subsystem in the engine model is the crankshaft system. The model of this system describes the conversion of chemical energy of fuel into mechanical energy. The mathematical expression of this subsystem can be written as in Eq. 7, ignoring the energy lost by the exhaust and cooling system.

$$
J_{m} \frac{d \omega_{m}}{d t}=M_{m}-M_{\text {load }}
$$

where $J_{m}$ is the inertia of the crankshaft, $\omega_{m}$ angular velocity, $M_{\text {load }}$ is torque generated by the engine ve is the torque from the dynamometer or powertrain. The torque indicated by $M_{m}$ is considered as a function dependent on intake manifold pressure, engine speed, ignition advance, AFR value and intake manifold temperature.

\subsection{Design of the rule-based, gain-scheduling PID controller}

In this section, fuzzy logic rules are defined for the determination of gain scheduling PID controller and its parameters [18]. As is known, the transfer function of a discrete-time PID controller can be defined as follows,

$$
u_{\text {inj }}(k)=K_{p} e_{\lambda}(k)+K_{i} T_{s} \sum_{m=1}^{p} e(m)+\frac{K_{d}}{T_{s}} \Delta e_{\lambda}(k)
$$

where, $e_{\lambda}(k)$ and $\Delta e_{\lambda}(k)$ indicate the error and change of the error, respectively, between the reference value in the AFR at the time of sampling $k . K_{p}, K_{i}$ and $K_{d}$ are proportional, integral and derivative gain parameters. In order to determine the gain parameters of the controller, firstly a proportional range is defined as $\left[K_{p, \min } K_{p, \text { maks. }}\right]$ and $\left[K_{d, \text { min }} K_{d, \text { maks. }}\right]$ For simplicity, these parameters have been normalized between 0 and $1 . K_{p, n}$ and $K_{d, n}$ are the normalized value of $K_{p}$, and $K_{d}$, respectively. After that, the relation between integral and derivative time constant is defined as for the integral gain parameter. Since $T_{i}=K_{p} / K_{i}$ and $T_{i}=K_{d} / K_{p}$ the integral gain is obtained as $K_{i}=K_{p}^{2} / \beta K_{d}$.

$K_{p, n}, K_{d, n}$ and $\beta$ parameters have been determined for fuzzification the error $e_{\lambda}(k)$ and the change of the error $\Delta e_{\lambda}(k)$. For this purpose, the triangle type membership function is used and is shown with Fig. 2.

In this Fig., N, P, S, M represents negative, positive, zero, and medium, respectively. Thus, NM is negative-medium,

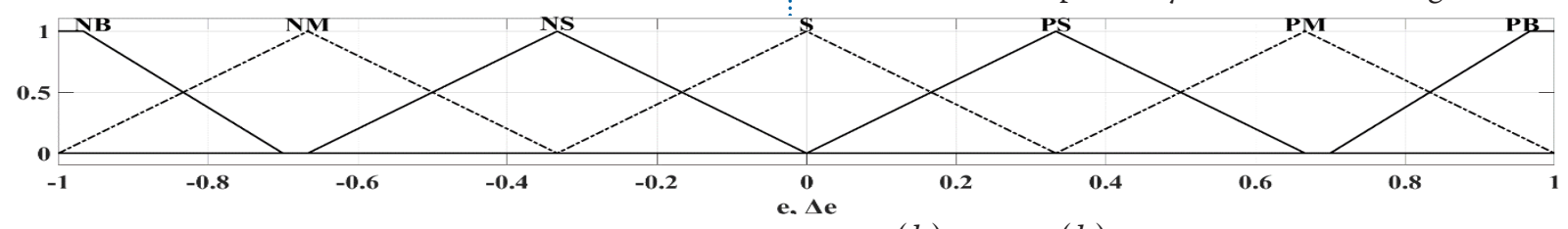

Figure 2. Membership functions for $e_{\lambda}(k)$ and $\Delta e_{\lambda}(k) \mathrm{i}$ 
PB is positive-large and so on. Fig. 3 shows the membership function which characterizes the proportional and derivative gain parameters to be low and high. Gauss function has been used as membership function and expressed mathematically in

$$
f=e^{\frac{-(x-\mu)^{2}}{2 \sigma^{2}}}
$$

where $x$ represents the input values, $\mu$ is the mean and $\sigma$ is the standard deviation.

Another parameter in the PID controller is the integral gain. The integral time constant is related to $\beta$ and by selecting this value small, the effect of the integral parameter in the controller can be increased, as indicated in Eq. 9. Ziegler Nichols rule can be used to decide whether to increase or decrease this effect [16]. According to this rule, it is stated that four times the ratio between the integral time constant and derivative should be maintained. In this study, a membership function is defined within the effect of integral, and this parameter is considered as output. The $\beta$ output variable is divided into four parts (K-small, M-medium, B-large). The membership function is shown in Fig. 4.

In fuzzy controllers, it is very important to determine the relationships between inputs and outputs of the system. This relationship can be created by preparing rule tables. The fact that the designer who prepared the table is experienced about the system is effective in increasing the performance of the controller. The rules have been based on minimizing the difference between the reference AFR and the sensor output. The rules determined according to the three parameters are given in Table 2.

The final stage of the fuzzy controller design is to clarify the fuzzy results obtained by the rules. For this purpose, the centre of gravity method proposed by Mamdani and Assilian has been used [19].

\subsection{Gray System Modeling Approach}

The gray model is generally defined as $G(q, r)$, where $q$ is the degree of differential equation to be created, and $r$ is the number of variables. Especially in real-time control applications,first-order differential equations are used. Thus, G $(1,1)$ model is obtained and named as a first-order linear gray model. The steps for the creation of this model are given below.

Under the assumption of a single input and a single output system, the system output X (0) is indicated by

$$
X^{(0)}=\left[X^{(0)}(1), X^{(0)}(2), \ldots, X^{(0)}(k)\right], k \geq 4
$$

where is the number of sample By applying the deposition production process to this array,

$$
\begin{aligned}
& X^{(1)}=\sum_{j=1}^{n} X^{(0)}(j), n=1,2,3, \ldots k \\
& X^{(1)}=\left[X^{(1)}(1), X^{(1)}(2), \ldots, X^{(1)}(k)\right]
\end{aligned}
$$

The mean array of the array $X^{(1)}$ is then generated,

$$
Z^{(1)}=\left[z^{(1)}(1), z^{(1)}(2), \ldots, z^{(1)}(k)\right]
$$

where;

$$
z^{(1)}(t)=\sigma X^{(1)}(t)+(1-\sigma) X^{(1)}(t-1), t=2,3, \ldots, k
$$

where $\sigma$ is generally taken as 0.5 . By using all this information, GM $(1,1)$ difference equation and first-order differential equation are defined as follows,

$$
\begin{aligned}
& X^{(0)}(t)+a z^{(1)}(t)=b \\
& \frac{d X^{(1)}}{d} t+a X^{(1)}=b
\end{aligned}
$$

\begin{tabular}{|c|c|c|c|c|c|c|c|c|c|c|c|c|c|c|c|c|c|c|c|c|c|c|}
\hline & \multicolumn{21}{|c|}{$\Delta e_{\lambda}(k)$} \\
\hline & & \multicolumn{3}{|c|}{ NB } & \multicolumn{3}{|c|}{ NM } & \multicolumn{3}{|c|}{ NK } & \multicolumn{3}{|c|}{$S$} & \multicolumn{3}{|c|}{ PK } & \multicolumn{3}{|c|}{ PM } & \multicolumn{3}{|c|}{ PB } \\
\hline & & $K_{p, n}$ & $K_{d, n}^{d}$ & $\beta$ & $K_{p, n}^{p}$ & $K_{d, n}$ & $\beta$ & $K_{p, n}$ & $K_{d, n}$ & $\beta$ & $K_{p, n}$ & $K_{d, n}$ & $\beta$ & $K_{p, n}$ & $K_{d, n}$ & $\beta$ & $K_{p, n}$ & $K_{d, n}$ & $\beta$ & $K_{p, n}$ & $K_{d, n}$ & $\beta$ \\
\hline \multirow{7}{*}{ 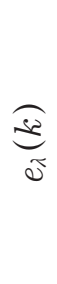 } & NB & Y & $\mathrm{D}$ & K & Y & D & $\mathrm{K}$ & Y & D & $\mathrm{K}$ & $Y$ & D & $\mathrm{K}$ & Y & D & $\mathrm{K}$ & $Y$ & D & K & Y & $\mathrm{D}$ & K \\
\hline & NM & D & Y & KO & Y & $Y$ & KO & $\mathrm{Y}$ & D & $\mathrm{K}$ & Y & D & $\mathrm{K}$ & Y & D & $\mathrm{K}$ & $Y$ & Y & KO & D & $\mathrm{Y}$ & $\mathrm{KO}$ \\
\hline & NK & D & $Y$ & $\mathrm{O}$ & D & $Y$ & $\mathrm{KO}$ & $\mathrm{Y}$ & $\mathrm{Y}$ & KO & $Y$ & D & $\mathrm{K}$ & Y & Y & KO & $\mathrm{D}$ & Y & KO & D & $Y$ & $\mathrm{O}$ \\
\hline & $S$ & D & $Y$ & B & D & $Y$ & $\mathrm{O}$ & $\mathrm{D}$ & Y & KO & $Y$ & Y & KO & $\mathrm{D}$ & Y & KO & $\mathrm{D}$ & Y & $\mathrm{O}$ & D & $\mathrm{Y}$ & B \\
\hline & PK & $\mathrm{D}$ & $Y$ & $\mathrm{O}$ & D & $Y$ & KO & $\mathrm{Y}$ & $\mathrm{Y}$ & KO & $Y$ & D & $\mathrm{K}$ & $Y$ & $\mathrm{Y}$ & KO & $\mathrm{D}$ & $Y$ & KO & $\mathrm{D}$ & $Y$ & $\mathrm{O}$ \\
\hline & PM & D & $Y$ & KO & $\mathrm{Y}$ & $Y$ & KO & $\mathrm{Y}$ & $\mathrm{D}$ & $\mathrm{K}$ & $Y$ & D & $\mathrm{K}$ & $Y$ & $\mathrm{D}$ & $\mathrm{K}$ & $Y$ & $Y$ & KO & $\mathrm{D}$ & $Y$ & KO \\
\hline & PB & $Y$ & $\mathrm{D}$ & $\mathrm{K}$ & $\mathrm{Y}$ & $\mathrm{D}$ & $\mathrm{K}$ & $Y$ & $\mathrm{D}$ & $\mathrm{K}$ & $Y$ & D & $\mathrm{K}$ & $Y$ & $\mathrm{D}$ & $\mathrm{K}$ & $Y$ & $\mathrm{D}$ & $\mathrm{K}$ & $Y$ & $\mathrm{D}$ & $\mathrm{K}$ \\
\hline
\end{tabular}

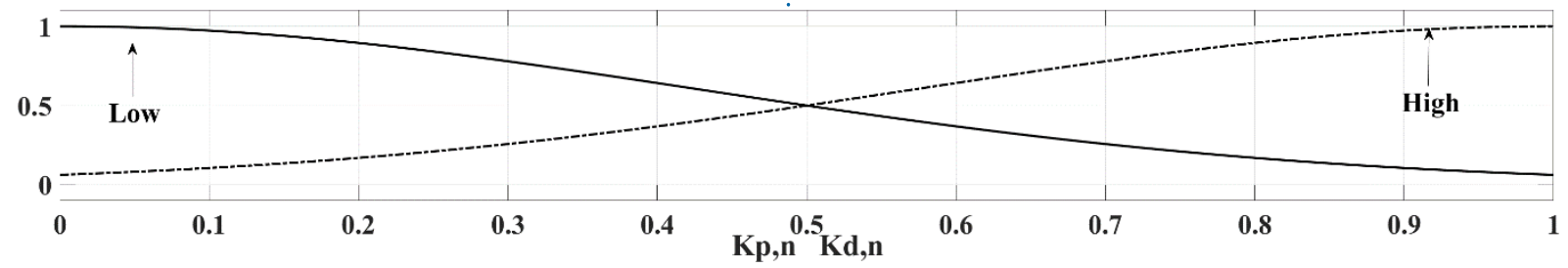

Figure 3. $K_{p, n}$ ve $K_{d, n}$ parametreleri için üyelik fonksiyonları

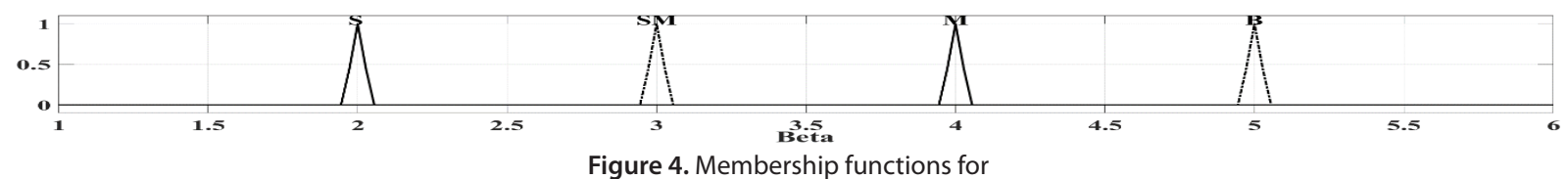

Table 2. Rule table for $K_{p, n}, K_{d, n}$ ve (D: Low; Y: High) 


$$
\left[\begin{array}{ll}
a & b
\end{array}\right]^{T}=\left(B^{T} B\right)^{-1} B^{T} Y
$$

where;

$$
Y=\left[X^{(0)}(2), X^{(0)}(3), \ldots, X^{(0)}(k)\right]^{T} \text {, ve } B=\left[\begin{array}{ccc}
-z^{(1)}(2) & 1 \\
-z^{(1)}(3) & 1 \\
\vdots & \vdots \\
-z^{(1)}(k) & 1
\end{array}\right]
$$

By solving the differential equation given in Eq. 15, the prediction value of $\hat{X}^{(1)}$ at time $t+1$ is obtained.

$$
\hat{X}^{(1)}(t+1)=\left(X^{(1)}-b / a\right) e^{-a k}+b / a
$$

\subsection{Design of Gray Based Fuzzy Gain-Scheduling PID Controller Design}

There are three input variables in a traditional controllers; the error, the derivative error and integral of error. The gray prediction algorithm used in this study has been designed to determine the relationship between the signal by generating an array of signal in the error feedback path and to predict its future value. The control signal is the output of the previous error function in the system in traditional control applications. However, one ahead prediction of error is used gray control systems. In this study, the fuzzy rule table and the gray predictor with the PID controller in which gain parameters are regulated are combined. For the gray predictor, the error signal array is given as e (k),e (k-1),e (k-2),e (k-3) have been acquised and the error value e $(k+1)$ has been calculated. The controller block diagram is shown in Fig. 5.

\section{RESULTS AND DISCUSSION}

In this study, two different control algorithms have been designed for variable engine operating conditions to investigate the performance of the proposed controller algorithm. In all tests, the desired AFR ratio has been set to 14.6. Vari- able engine operating conditions have been achieved only by changing the throttle valve opening ratio.Two different scenarios are emphasized in this study for variable engine operating conditions. The first is the US06 driving cycle, defined as high-speed aggressive driving and it takes about 600 seconds. The second application, the UDDS (Urban Dynamometer Driving Schedule) cycle, is called "city test" and is used to test urban driving conditions. The data for the driving cycles have been obtained from the official web site of the Environmental Protection Agency (EPA).

In the two driving cycles mentioned above, AFR has been tried to keep in stoichiometric value, firstly with the classical PID, then with the controller structure proposed in the study. The gain parameters in the classical PID structure defined by Eq. 8 have been optimally determined by the pattern search algorithm as $K_{p}=10.8587, K_{I}=1.5723$ and $K_{D}=1.5353$.

Then, the data file for engine speed for the US06 driving cycle has been transferred to the Simulink environment (Fig. 6). The system parameters are given in Table 3.

Table 3. The system parameters used in the simulation

\begin{tabular}{|c|c|}
\hline \multicolumn{2}{|c|}{ Parameters } \\
\hline İdeal gas constant (air) & $287(\mathrm{~J} /(\mathrm{kgK}))$ \\
\hline Intake manifold pressure & 101325 \\
\hline Intake air temperature & 293.15 \\
\hline The mass flow rate of the fuel & 30 Crank Angle \\
\hline Ignition advance & $\mathrm{Nm}$ \\
\hline Engine load & $\mathrm{Dm}$ \\
\hline
\end{tabular}

The variation of AFR for the conventional PID controller during the US06 cycle is shown in Fig. 7.

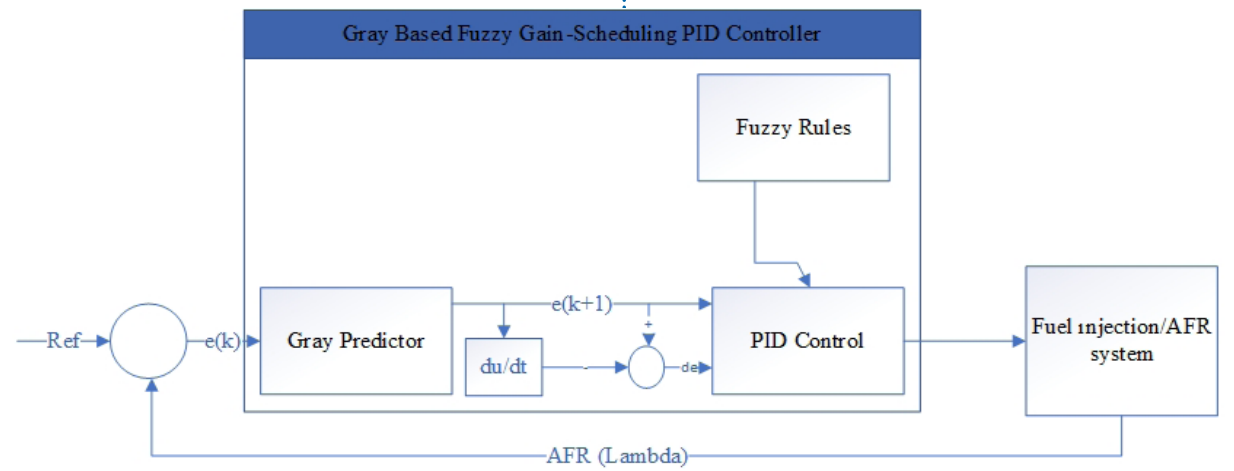

Fig. 5. The gray predictive and gain scheduling fuzzy PID controller

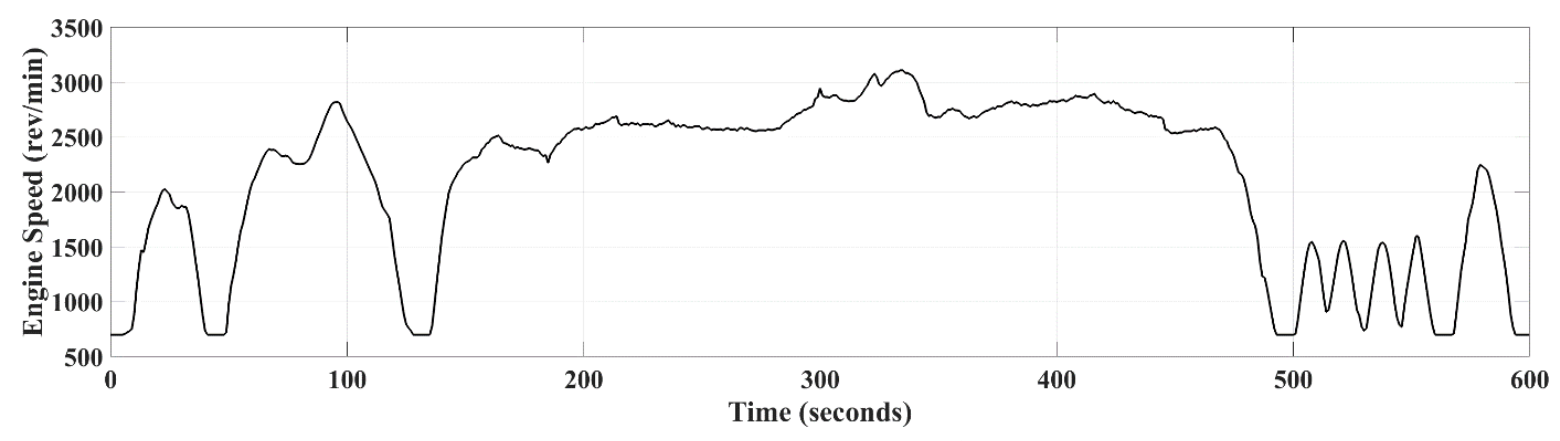

Fig. 6. The engine speed and throttle opening ratio for driving cycle US06 
As can be seen from the Fig., the controller is forced to keep the AFR ratio at 14.6 with the change in speed during the first 150 seconds. Between 200 and 490 seconds of the test cycle, the engine operates at constant speed. In this case, it is observed that the deviation of AFR from the stoichiometric ratio is quite low.

Secondly, the AFR values obtained by using the controller proposed in this study during US06 cycle conditions are shown in Fig. 8.

However, when the proposed controller is applied, the deviation of the AFR from the reference value has been reduced compared to the conventional method. In order to visualize the error change for both controllers, Fig. 9 has been plotted.

Fig. 9 shows 50\% difference between controllers for the error value at some points of the cycle.

Secondly, the UDDS cycle has been applied. The the engine speed during the cycle is given in Fig. 10.

The variations of AFR in the case of conventional PID is shown in Fig. 11.

As can be seen in Fig. 11, the variation of AFR is highly affected by the change in the throttle opening ratio. The vari-

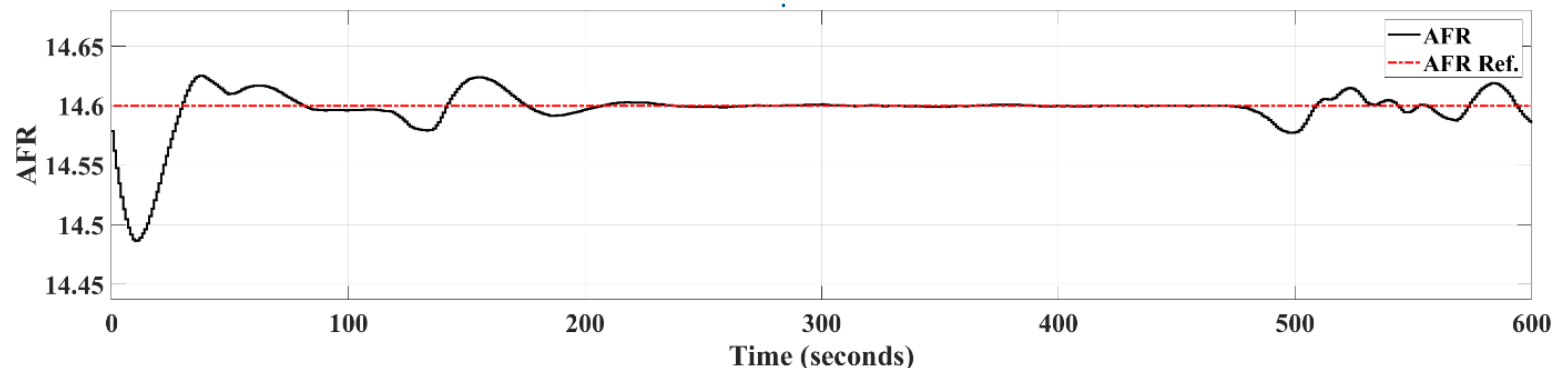

Figure 7. Variation of AFR during the US06 cycle when conventional PID is applied

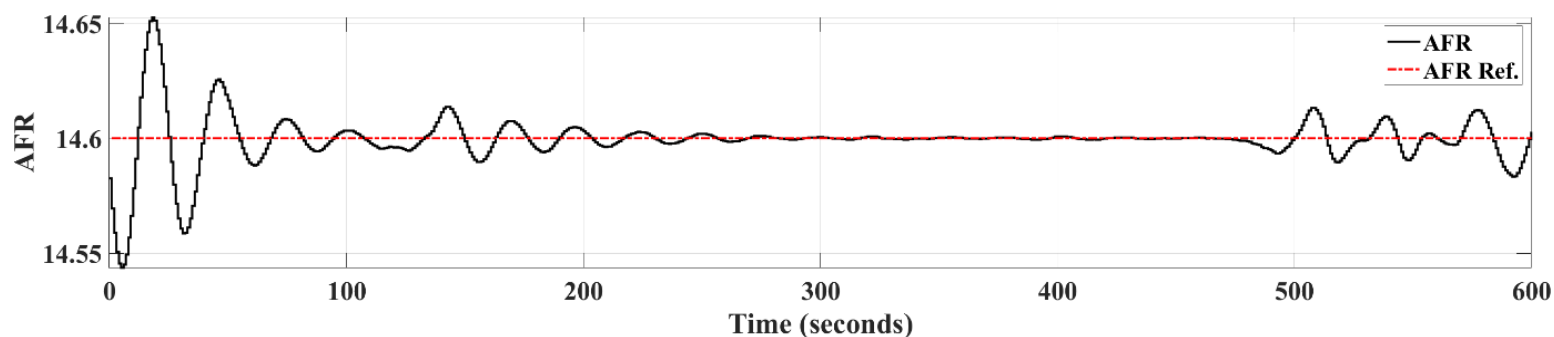

Figure 8. Variation of AFR during the US06 cycle when the proposed controller is applied

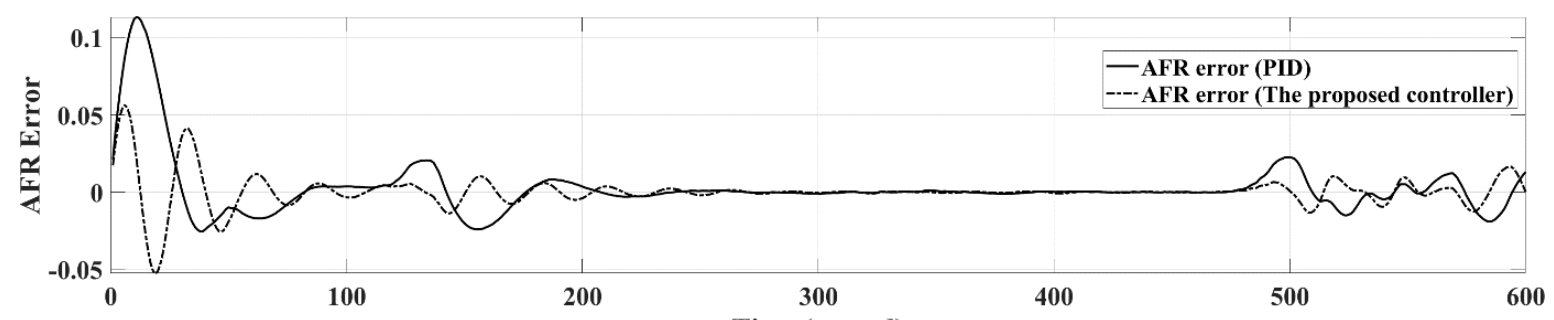

Figure 9. Error performance variations of both controllers during the US06 cycle

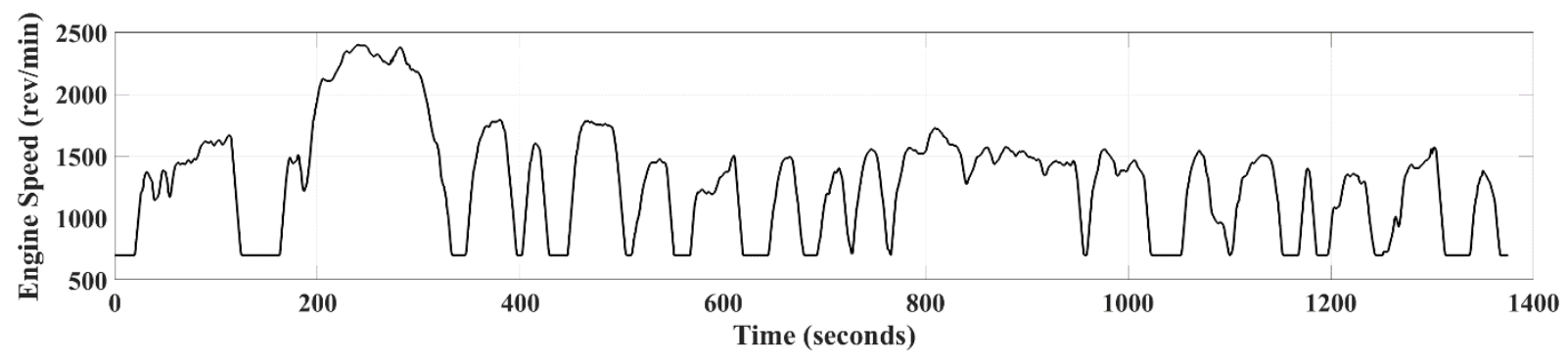

Figure 10. The engine speed and throttle opening ratio for driving cycle UDDS

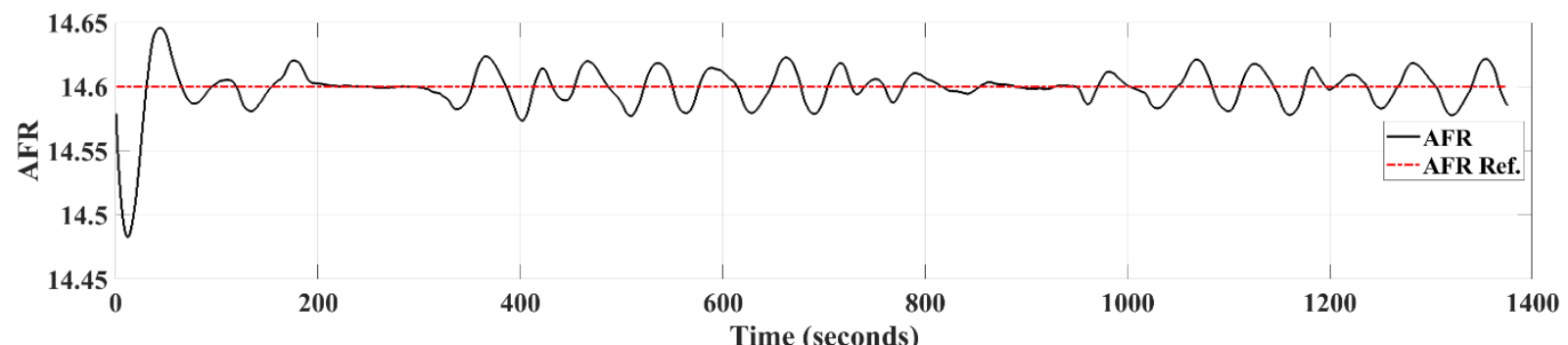

Figure 11. Variation of AFR during the UDDS cycle when conventional PID is applied 


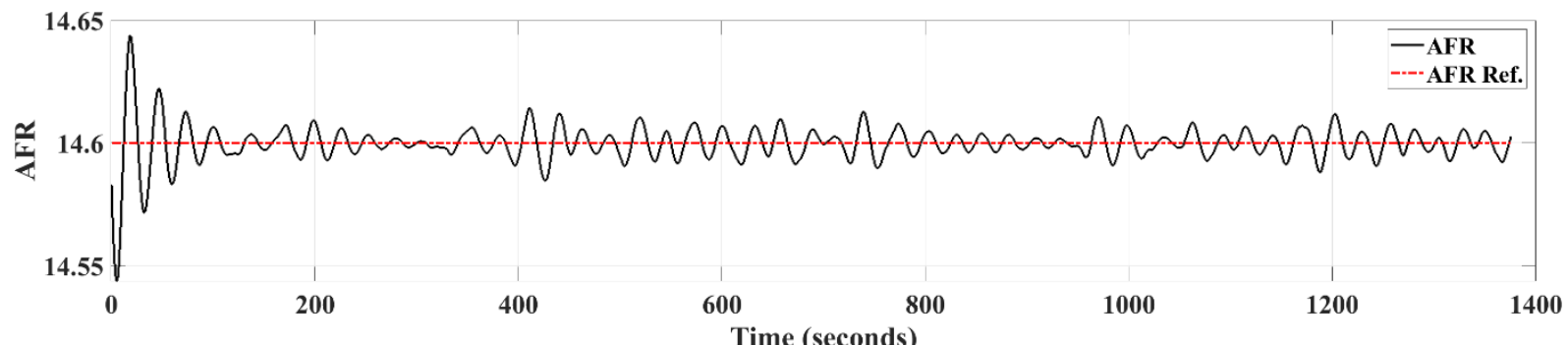

Figure 12. Variation of AFR during the UDDS cycle when the proposed controller is applied

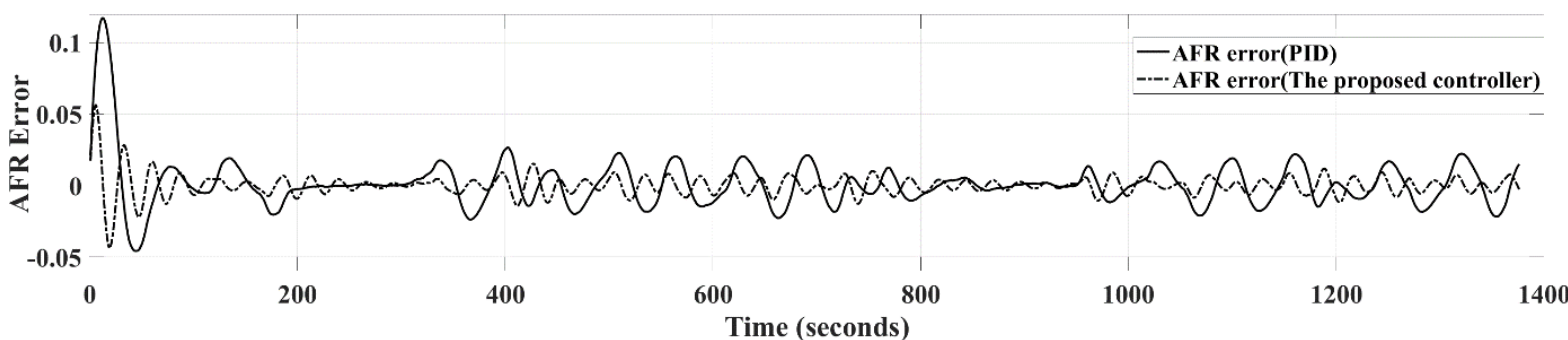

Figure 13. Error performance variations of both controllers during UDDS cycle
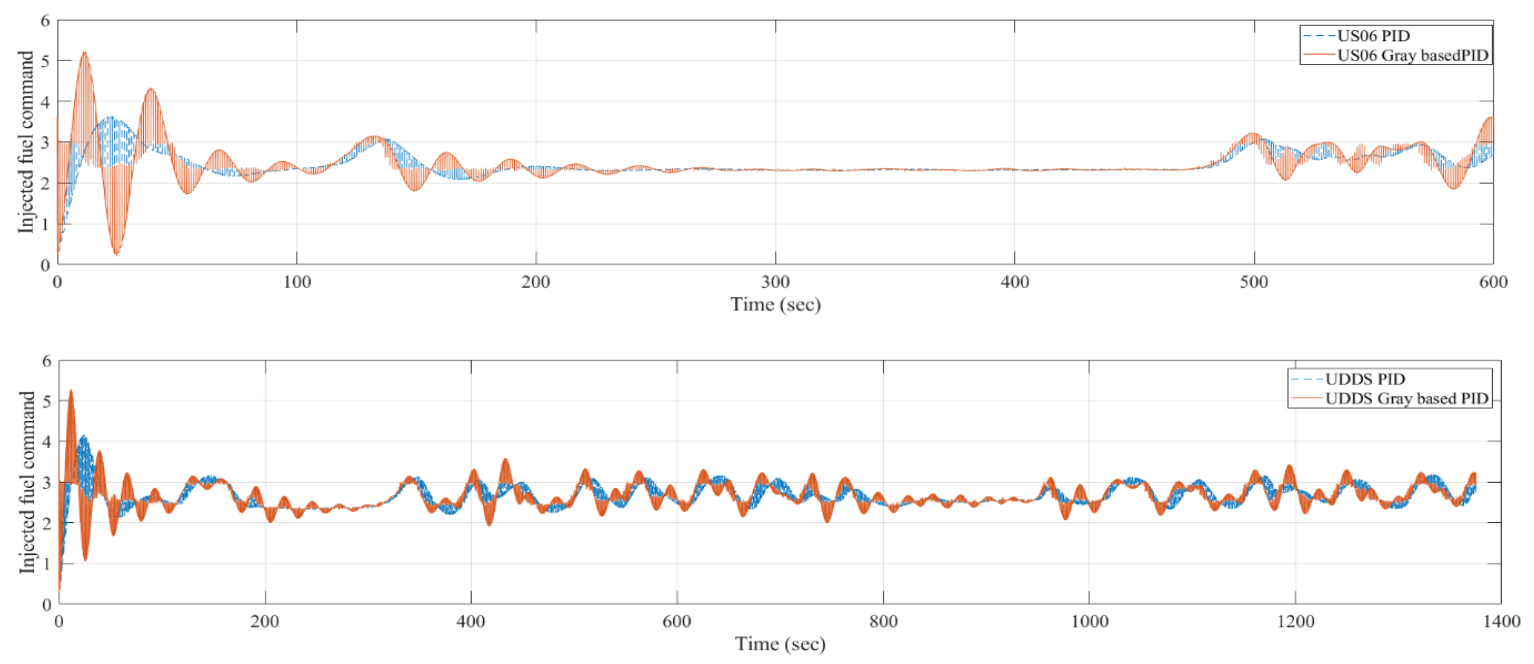

Figure 14. The control signal for US06 and UDDS driving cycle conditions

ation of AFR that occurs when the proposed controller is applied is given in Fig. 12.

It can be seen from this Figure, the oscillations of the AFR increase around the reference value. Since the gain parameters of the proposed controller have been adjusted adaptively in accordance with the variable conditions of the system, the sensitivity of the conventional PID to these oscillations is higher than the proposed controller. The error plot is shown in Fig. 13. The controller signals are given in Fig. 14.

In order to evaluate the proposed gray based fuzzy gain-scheduled PID controller in terms of error performance, the MSE and MAE values of the AFR in both driving cycles are given in Table 3.

Table 4. MSE and MAE values for both driving cycles

\begin{tabular}{|c|c|c|c|c|}
\hline \multirow{2}{*}{$\begin{array}{c}\text { Drive } \\
\text { Cycles }\end{array}$} & \multicolumn{2}{|c|}{ Mae (Mean absolute error) } & \multicolumn{2}{|c|}{ Mse (Mean square error) } \\
\cline { 2 - 5 } & PID & $\begin{array}{c}\text { Proposed Cont- } \\
\text { roller }\end{array}$ & PID & $\begin{array}{c}\text { Proposed } \\
\text { Controller }\end{array}$ \\
\hline US06 & 0.0085 & 0.0051 & $3.6843 \mathrm{e}-04$ & $1.1119 \mathrm{e}-04$ \\
\hline UDDS & 0.0108 & 0.0048 & $3.0184 \mathrm{e}-04$ & $5.5098 \mathrm{e}-05$ \\
\hline
\end{tabular}

As can be seen from Table 3, the steady-state error performance value of the optimally adjusted PID controller is approximately twice that of the proposed controller structure. This situation reveals the superiority of the proposed controller in terms of performance according to the conventional controller.

\section{CONCLUSIONS}

In this study, two different controllers (The conventional PID and gray based fuzzy gain-scheduled PID controller) have been designed to control the fuel injectors to regulate the AFR in gasoline engines. Firstly, a mathematical model of the air and exhaust path dynamics of the engine is formulated as mean value engine modelling technique. Then, error fuzzy rules are developed. The conventional PID and proposed gray based, fuzzy gain-scheduling fuzzy PID methods have been applied on the AFR system in order to improve stoichiometric AFR regulating the performance of the control approaches. The gain parameters of the conventional PID are optimally adjusted using the pattern search opti- 
mization method. The US06 and UDDS driving cycles have been used to analyze the performance of the hybrid controller, especially in variable engine operating conditions. According to the MSE and MAE data between the desired and actual AFR values, the results obtained in the case of using gray predictive, gain scheduling fuzzy PID are better than the PID with optimally adjusted gains. The main advantage of the proposed control design is a systematic solution for the nonlinear AFR system. Future works are concerning the extension of the proposed controller to independent cylinder AFR regularization. Simulation results showed that the designed gray base GS-PID AFR system outperforms compared to the conventional PID system in terms of reducing the MSE, with a $5.8 \%$ and $50.4 \%$ reduction, respectively.

\section{REFERENCES}

[1] Manzie, C., Palaniswami, M., Ralph, D., Watson, H., Yi, X., (2002). Model Predictive Control of a Fuel Injection System with a Radial Basis Function Network Observer. Journal of Dynamic Systems, Measurement, and Control, Doi: 10.1115/1.1515328.

[2] Franceschi, E.M., Muske, K.R., Peyton Jones, J.C., Makki, I., (2007). An Adaptive Delay-Compensated PID Air Fuel Ratio Controller, Doi: https://doi.org/10.4271/2007-01-1342.

[3] Pace, S., Zhu, G.G., (2014). Transient air-to-fuel ratio control of an spark ignited engine using linear quadratic tracking. Journal of Dynamic Systems, Measurement, and Control 136(2): 21008.

[4] Ebrahimi, B., Tafreshi, R., Masudi, H., Franchek, M., Mohammadpour, J., Grigoriadis, K., (2012). A parameter-varying filtered PID strategy for air-fuel ratio control of spark ignition engines. Control Engineering Practice 20(8): 805-15, Doi: 10.1016/j.conengprac.2012.04.001.

[5] Hendricks, E., Chevalier, A., Jensen, M., Sorenson, S.C., Trumpy, D., Asik, J., (1996). Modelling of the Intake Manifold Filling Dynamics, Doi: https://doi.org/10.4271/960037.

[6] Jones, V.K., Ault, B.A., Franklin, G.F., Powell, J.D., (1995). Identification and air-fuel ratio control of a spark ignition engine. Control Systems Technology, IEEE Transactions On 3(1): 14-21, Doi: 10.1109/87.370705.

[7] Tseng, T.-C., Cheng, W.K., (1999). An Adaptive Air/Fuel Ratio Controller for SI Engine Throttle Transients, Doi: https://doi. org/10.4271/1999-01-0552.

[8] Al-Olimat, K.S., Ghandakly, A.A., Jamali, M.M., (2000). Adaptive Air-Fuel Ratio Control of an SI Engine Using Fuzzy Logic Parameters Evaluation, Doi: 10.4271/2000-01-1246.

[9] Wang, S.W., Yu, D.L., Gomm, J.B., Page, G.F., Douglas, S.S., (2006). Adaptive neural network model based predictive control for air-fuel ratio of SI engines. Engineering Applications of Artificial Intelligence 19(2): 189-200, Doi: https://doi.org/10.1016/j.engappai.2005.08.005

[10] Suzuki, K., Tielong, S., Kako, J., Yoshida, S., (2009). Individual A/F Estimation and Control With the Fuel\&\#x2013;Gas Ratio for Multicylinder IC Engines. Vehicular Technology, IEEE Transactions On 58(9): 4757-68, Doi: 10.1109/TVT.2009.2025862.

[11] Ljung, L., (1998). System Identification: Theory for the User. Pearson Education.

[12] Han, P., Liu, H.-J., Meng, L.-M., Wang, N., (2005). Research of grey predictive fuzzy controller for large time delay system. 2005 International Conference on Machine Learning and Cybernetics, vol. 2. IEEE p. 829-33.
[13] Kayacan, E., Kaynak, O., (2009). An adaptive grey PID-type fuzzy controller design for a non-linear liquid level system. Transactions of the Institute of Measurement and Control 31(1): 33-49.

[14] Kudinov, Y.I., Kolesnikov, V.A., Pashchenko, F.F., Pashchenko, A.F., Papic, L., (2017). Optimization of Fuzzy PID Controller's Parameters. Procedia Computer Science 103: 618-22, Doi: https://doi.org/10.1016/j.procs.2017.01.086.

[15] Liu, H., Li, Y., Zhang, Y., Chen, Y., Song, Z., Wang, Z., et al., (2018). Intelligent tuning method of PID parameters based on iterative learning control for atomic force microscopy. Micron 104: 26-36, Doi: https://doi.org/10.1016/j.micron.2017.09.009.

[16] K. Ogata., (2002). Modern Control Engineering.

[17] Heywood, J., (1988). Internal Combustion Engine Fundamentals. McGraw-Hill Education.

[18] Zhao, Z.Y., Tomizuka, M., Isaka, S., (1992). Fuzzy gain scheduling of PID controllers. Proceedings of the 1st IEEE Conference on Control Applications, CCA 1992,

[19] Mamdani, E.H., Assilian, S., (1975). An experiment in linguistic synthesis with a fuzzy logic controller. International Journal of Man-Machine Studies, Doi: 10.1016/S0020-7373(75)80002-2. 